\title{
Far-field coseismic displacements associated with the 2011 Tohoku-oki earthquake in Japan observed by Global Positioning System
}

\author{
WANG Min ${ }^{1 *}$, LI Qiang ${ }^{2}$, WANG Fan ${ }^{1}$, ZHANG Rui ${ }^{2}$, WANG YanZhao ${ }^{1}$, SHI HongBo ${ }^{2}$, \\ ZHANG PeiZhen ${ }^{1} \&$ SHEN ZhengKang ${ }^{3}$ \\ ${ }^{1}$ State Key Laboratory of Earthquake Dynamics, Institute of Geology, China Earthquake Administration, Beijing 100029, China; \\ ${ }^{2}$ National Earthquake Infrastructure Service, China Earthquake Administration, Beijing 100036, China; \\ ${ }^{3}$ Department of Geophysics, School of Earth and Space Science, Peking University, Beijing 100871, China
}

Received April 6, 2011; accepted May 20, 2011

\begin{abstract}
Analysis of GEONET observations covering the entire territory of Japan shows that the great Tohoku-oki earthquake that occurred on March 11, 2011 off the east coast of Honshu in Japan caused an eastward movement of the northern part of the island by as much as $5.3 \mathrm{~m}$. The GPS data from TEONET in China were used to derive far-field coseismic displacements and to assess the impact of the Tohoku-oki earthquake on crustal deformation in eastern China. The results reveal that the coseismic horizontal displacements induced by the earthquake are the level of millimeters to centimeters in North and Northeast China, with a maximum of $35 \mathrm{~mm}$. Strain analysis also indicates that the earthquake resulted in an increase in the tensile strain on the north-northeast trending faults in North and Northeast China. The tensile strain imposed on the Yilan-Yitong and Dunhua-Mishan faults is more significant than that imposed on the faults in North China; the maximum normal strain reaches about 40 nano-strain. Considering that the static Coulomb stress loaded on the faults is limited, its effect on the regional seismic activity may not be significant.
\end{abstract}

Tohoku-oki earthquake, far-field coseismic displacement, Tan-Lu fault zone, stress-strain, seismic activity

Citation: Wang M, Li Q, Wang F, et al. Far-field coseismic displacements associated with the 2011 Tohoku-oki earthquake in Japan observed by Global Positioning System. Chinese Sci Bull, 2011, 56: 2419-2424, doi: 10.1007/s11434-011-4588-7

On March 11, 2011, a huge $M_{\mathrm{w}} 9.0$ earthquake occurred off the Pacific coast of northeastern Japan. The earthquake and the triggered tsunami caused massive destruction and huge numbers of casualties. According to the Japanese official statistics, as of April 4, the death toll exceeded 12000, more than 15000 people were reported missing, and the actual death toll was estimated to be over 27000 . In northeastern Honshu, a large number of towns and villages located in the coastal area were swept out to the sea by the tsunami, and the four nuclear reactors of the Fukushima nuclear power plant were damaged and leaked radioactive contaminants into the air and water. The situation is still unfolding and it is difficult to evaluate its long-term effects.

*Corresponding author (email: mwang@gps.gov.cn)
The Japanese islands are located on the northwest rim of the Pacific Ocean, at the junction of the Pacific, North American, Philippine Sea and Eurasian plates. The earthquake occurred on the subduction zone between the Pacific and North American tectonic plates, in which the Pacific Plate moves westward at a rate of $\sim 80 \mathrm{~mm} / \mathrm{a}$ relative to the Eurasian Plate and eventually plunges underneath the North American Plate [1]. After the earthquake, many research institutions provided focal mechanism solutions, which all indicated that the earthquake occurred on the upper interface of the subducting slab, the rupture plane dipped to the west at an angle of $9^{\circ}-14^{\circ}$, and the released seismic moment was about $3.6 \times 10^{22} \mathrm{Nm}$, equivalent to a $M_{\mathrm{w}} 9.0$ earthquake (Earthquake Research Institute, the University of Tokyo, http://www.eri.u-tokyo.ac.jp; United State Geological Survey (USGS), http://earthquake.usgs.gov; Harvard University, 
http://www.seismology.harvard.edu), making it the fourth largest earthquake recorded by seismic instrumentation over the last century. The aftershock distribution showed that the rupture plane was $\sim 100 \mathrm{~km}$ wide and extended $\sim 350 \mathrm{~km}$ in a north-south direction along strike (USGS, http://earthquake. usgs.gov; Japanese Meteorological Agency, http://www.jma. go.jp/en/quake). Seismic waveform inversion has revealed that the rupture started at $38.1^{\circ} \mathrm{N}, 142.8^{\circ} \mathrm{E}$ and $\sim 26 \mathrm{~km}$ deep, followed by a two-way rupture propagation with the largest slip of $\sim 25 \mathrm{~m}$, but dominated by thrust slip (http://www.geol. tsukuba.ac.jp/ yagi-y/EQ/Tohoku/index-e.html).

Since most of the earthquake rupture is located under the sea, detection of the rupture process relies on tele-recorded measurements. In addition to data from global and regional seismic networks, Global Positioning System (GPS) observations from Japan and its neighboring regions on the Asian continent are particularly important. After the earthquake, the ARIA team from JPL and Caltech made a rapid analysis of the data from GPS Earth Observation Network (GEO NET) and produced a coseismic displacement field for the Japanese islands (ftp://sideshow.jpl.nasa.gov/pub/usrs/ ARIA/ARIA_coseismic_offsets.v0.3.table). The results show a considerable amount of eastward motion of northern Honshu and the horizontal displacement reached a maximum of $\sim 5.3 \mathrm{~m}$, with $\sim 1.1 \mathrm{~m}$ of subsidence on the east coast. On the west coast of northern Honshu, $\sim 0.7 \mathrm{~m}$ of horizontal displacement was found. The GPS displacement data were used to invert for the slip distribution of fault rupture and a maximum slip of $\sim 21 \mathrm{~m}$ was obtained (http://earthquake.usgs. gov/earthquakes/world/japan/031111_M9.0prelim_geodetic_ slip.php), which is comparable to the result obtained from seismic waveform inversion.

The coseismic displacement field obtained from the GPS stations in Japan provides information about near- and intermediate-field deformation. However, how is the far-field coseismic deformation distributed? What is the scope of its impact? Are the regions of Northeast and North China affected? If the coseismic effect exists, in what form does it appear? How does it impact the tectonic stress field in the Chinese continent? Answers to the above questions will not only help to understand the seismogenic structure and spatial distribution of slip for the Tohoku-oki earthquake, but also are essential in assessing the effect on the earthquake potential in North and Northeast China.

The national key infrastructure project "Tectonic and Environmental Observation Network in China" (hereinafter referred to as TEONET) provides important data for far-field seismic displacement monitoring. Construction of TEONET was completed in 2010 and primarily incorporates GPS technology to monitor crustal deformation. TEONET includes 260 continuous GPS stations, covering the entire Chinese continent, and its facilities are currently under trial operation. We have analyzed the GPS data from TEONET to derive the crustal deformation field in eastern China caused by the Tohoku-oki earthquake.
GAMIT software [2] was used to process the GPS data observed between March 8 and 13, 2011, from nearly 100 International Global Navigation Satellite System Service (IGS) stations and nearly 80 TEONET stations. Data recorded in an 18-h window on March 11 in the postseismic time period (06:00-24:00 UTC time) were used. For the IGS stations in Japan, the postseismic epoch was deduced using only the data observed on March 11, 06:00-24:00 UTC time. The GPS kinematic displacement results presented by the ARIA team showed continuous westward motion for the GEONET stations in the epicentral region after the quake, reaching a maximum of $\sim 0.4 \mathrm{~m}$ at a coastal site during the period of 5:55-14:00 UTC time on March 11 (ftp://sideshow.jpl.nasa.gov/pub/usrs/ARIA/ARIA_postseismic_offsets.v0.3.table). Therefore, the displacements of IGS stations in Japan derived from 18-h data collected after the main shock must contain significant postseismic deformation signals. However, postseismic deformation in Japan should not have a significant impact on our analysis of far-field coseismic displacements. In addition, including the IGS stations in our processing helps establish a unified and self-consistent reference frame, providing assurance of a reliable result.

Figure 1 and Table 1 display the result of far-field coseismic displacements, from which it can be seen that the earthquake has induced significant coseismic horizontal displacements in Northeast China, North China, and the Korean Peninsula. A maximum displacement of $\sim 35 \mathrm{~mm}$ in the south-southeast direction is observed near the triple border junction of China, Korea and Russia. The Korean Peninsula moved $\sim 20 \mathrm{~mm}$ eastward. Displacements on the level of millimeters to centimeters in an east-west oriented direction are observed in the coastal area of North China; for example, 6-9 $\mathrm{mm}$ in Beijing and 8-9 $\mathrm{mm}$ in Tianjin respectively. Millimeter level displacements are detected in the coastal area of East China. The displacement field decays rapidly westward, and approaches zero in western China such as in Lanzhou, Chengdu and Kunming, and in northern Eurasia such as the region of Lake Baikal. The displacement vectors of IGS stations in Japan are similar to those given by the ARIA team. The overall deformation pattern agrees with that which was predicted by a thrust dislocation model in an elastic half-space [3]. The vertical coseismic displacements are too small to be detected.

Up to now, the coseismic slip distribution models of the Tohoku-oki earthquake have been all obtained from the inversion of seismic waveform data and/or GPS coseismic displacement data in Japan. Without constraints from farfield coseismic displacement data, how accurate would these models be? To answer this question, we used the farfield coseismic displacement data to test the slip distribution model by Wei et al. obtained from the inversion of GPS coseismic displacement and seismic waveform data (http:// www.tectonics.caltech.edu/slip_history/2011_taiheiyo-oki/\# slip). Forward prediction of Wei et al.'s model shows that 


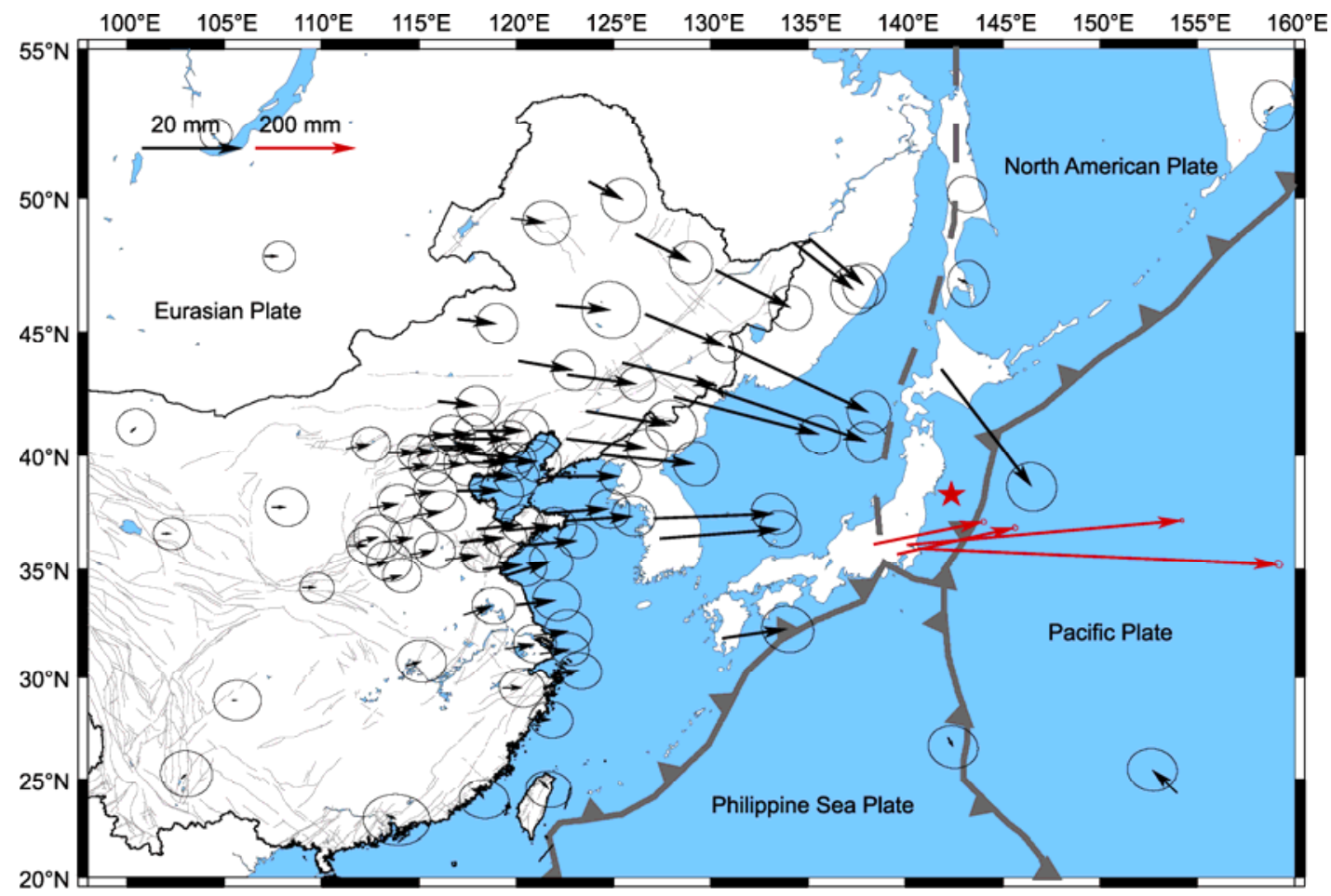

Figure 1 GPS-observed coseismic displacements in eastern China associated with the Tohoku-oki earthquake. The error ellipses represent $90 \%$ confidence.

systematic bias at the centimeter level exist between the observed and predicted data in the northeastern region of China, at the border between China and Russia, although the model fits most of the coseismic displacements in eastern China well. While the cause of the bias will be studied in the future, the far-field coseismic displacement data will provide help in refining the earthquake rupture model.

Whether or not the Tohoku-oki earthquake would affect local seismic activity in Northeast and North China is of particular concern. Ji (http://bbs.sciencenet.cn) proposed that the Tan-Lu fault zone in eastern China and the JapanIzu-Bonin trench system belong to the same geological structure, and it is worth paying attention to the impact of the subduction of the Pacific Plate on the Tan-Lu fault zone. Previous studies considered that the westward subduction of the Pacific Plate caused deep-focused seismic activities in Northeast China, and further affected shallow seismic activities in Northeast and North China [4,5]. Li et al. [6] analyzed the seismicity pattern of $>M 6$ events in North China and $>M 7$ events in the arc-trench region off Japan, and found that the uneven distributions of the two groups of earthquakes over time have a certain pattern of synchronization. We therefore performed a brief analysis on the Tohokuoki earthquake induced change in regional strain and possible seismic activity after the quake.

First, we derived the horizontal strain field by interpolating the GPS coseismic displacement field using the method of Shen et al. [7]. Figure 2 shows the horizontal principal strain components and reveals that the Tohoku-oki earth- quake produced tensile strain on the north-northeast trending faults in North and Northeast China. The tensile strain imposed on the northern extensions of the Tan-Lu fault zone (also named as the Yilan-Yitong and Dunhua-Mishan faults) is relatively significant, with the maximum up to about 40 nano-strain. Assuming a shear modulus of $3.0 \times$ $10^{10} \mathrm{~Pa}$ and the inner friction coefficient of 0.8 for the faults, and taking into account the change in the shear stress as well, we estimate that the maximum static Coulomb stress loaded by the coseismic deformation field would not exceed $0.002 \mathrm{MPa}$. The latest research showed that the Yilan-Yitong fault was tectonically active in Holocene and controlled the occurrence of small and moderate earthquake activities in Northeast China [8]. Therefore, the Tohoku-oki earthquake may have some minor effects on the seismic activity of the Yilan-Yitong fault, but little effect on other segments of the Tan-Lu fault zone and other faults in eastern China.

Our calculation also shows that Changbaishan volcano is located in a region of areal expansion caused by the Tohokuoki earthquake (Figure 2). This means that the earthquake might cause the opening of the magma channel of the volcano and thus assist ascension of the magma flow [9]. Therefore, the earthquake could cause an increase in the activity of Changbaishan [10].

Second, we performed a statistical analysis on earthquake frequency from June 1, 2010 to March 31, 2011 in Northeast and North China (Figure 3). The results reveal that in these two regions, seismic activities do not increase significantly within three weeks after the earthquake, which 
Table 1 GPS observed coseismic displacements associated with the Tohoku-oki earthquake

\begin{tabular}{|c|c|c|c|c|c|}
\hline \multirow{2}{*}{ Station } & \multicolumn{2}{|c|}{ Station location } & \multicolumn{3}{|c|}{ Coseismic displacement } \\
\hline & Longitude $\left({ }^{\circ}\right)$ & Latitude $\left(^{\circ}\right)$ & East (m) & North (m) & Correlation \\
\hline AHBB & 117.296 & 32.905 & $0.005 \pm 0.0019$ & $0.002 \pm 0.0018$ & -0.043 \\
\hline BJFS & 115.892 & 39.609 & $0.006 \pm 0.0021$ & $0.000 \pm 0.0021$ & -0.042 \\
\hline BJGB & 117.158 & 40.692 & $0.009 \pm 0.0018$ & $0.000 \pm 0.0018$ & -0.048 \\
\hline BJSH & 116.224 & 40.251 & $0.008 \pm 0.0019$ & $0.000 \pm 0.0018$ & -0.044 \\
\hline BJYQ & 115.968 & 40.370 & $0.008 \pm 0.0018$ & $0.000 \pm 0.0017$ & -0.045 \\
\hline CHUN & 125.444 & 43.790 & $0.018 \pm 0.0018$ & $-0.006 \pm 0.0018$ & -0.057 \\
\hline DLHA & 97.378 & 37.381 & $0.001 \pm 0.0018$ & $0.000 \pm 0.0017$ & 0.012 \\
\hline DXIN & 100.201 & 40.984 & $0.001 \pm 0.0018$ & $0.001 \pm 0.0018$ & 0.002 \\
\hline GUAN & 113.340 & 23.185 & $0.002 \pm 0.0031$ & $-0.001 \pm 0.0025$ & -0.043 \\
\hline НАНВ & 114.519 & 35.658 & $0.005 \pm 0.0019$ & $0.001 \pm 0.0018$ & -0.045 \\
\hline HAJY & 112.447 & 35.163 & $0.004 \pm 0.0021$ & $0.001 \pm 0.0019$ & -0.029 \\
\hline HECC & 115.840 & 40.884 & $0.008 \pm 0.0020$ & $0.000 \pm 0.0020$ & -0.051 \\
\hline HECD & 117.918 & 41.016 & $0.010 \pm 0.0021$ & $0.000 \pm 0.0020$ & -0.049 \\
\hline HECX & 116.931 & 38.465 & $0.008 \pm 0.0020$ & $0.000 \pm 0.0019$ & -0.052 \\
\hline HELQ & 114.309 & 38.247 & $0.006 \pm 0.0020$ & $0.001 \pm 0.0020$ & -0.042 \\
\hline HELY & 114.707 & 37.399 & $0.006 \pm 0.0021$ & $0.001 \pm 0.0020$ & -0.045 \\
\hline HETS & 118.295 & 39.736 & $0.010 \pm 0.0021$ & $0.000 \pm 0.0020$ & -0.053 \\
\hline HEYY & 114.156 & 40.127 & $0.007 \pm 0.0019$ & $0.000 \pm 0.0018$ & -0.046 \\
\hline HEZJ & 114.900 & 40.828 & $0.007 \pm 0.0021$ & $0.000 \pm 0.0020$ & -0.049 \\
\hline HLAR & 119.741 & 49.270 & $0.006 \pm 0.0022$ & $-0.001 \pm 0.0022$ & -0.108 \\
\hline HLFY & 134.277 & 48.367 & $0.011 \pm 0.0022$ & $-0.010 \pm 0.0024$ & -0.042 \\
\hline HLHG & 130.236 & 47.353 & $0.015 \pm 0.0020$ & $-0.008 \pm 0.0022$ & -0.045 \\
\hline HLWD & 126.136 & 48.671 & $0.010 \pm 0.0020$ & $-0.005 \pm 0.0021$ & -0.038 \\
\hline HRBN & 126.620 & 45.703 & $0.015 \pm 0.0016$ & $-0.007 \pm 0.0016$ & -0.045 \\
\hline JIXN & 117.530 & 40.076 & $0.009 \pm 0.0016$ & $-0.001 \pm 0.0015$ & -0.047 \\
\hline JLCB & 128.106 & 42.411 & $0.029 \pm 0.0019$ & $-0.009 \pm 0.0019$ & -0.060 \\
\hline JLYJ & 129.505 & 42.875 & $0.033 \pm 0.0019$ & $-0.012 \pm 0.0020$ & -0.058 \\
\hline JSLS & 119.419 & 31.349 & $0.006 \pm 0.0020$ & $0.001 \pm 0.0019$ & -0.049 \\
\hline JSLY & 119.467 & 34.722 & $0.009 \pm 0.0020$ & $0.003 \pm 0.0019$ & -0.066 \\
\hline JSNT & 120.890 & 31.953 & $0.006 \pm 0.0022$ & $0.001 \pm 0.0021$ & -0.056 \\
\hline JSYC & 120.019 & 33.376 & $0.008 \pm 0.0022$ & $0.001 \pm 0.0020$ & -0.056 \\
\hline KUNM & 102.797 & 25.030 & $0.001 \pm 0.0023$ & $0.001 \pm 0.0023$ & -0.035 \\
\hline LNDD & 124.327 & 40.032 & $0.019 \pm 0.0021$ & $-0.002 \pm 0.0021$ & -0.066 \\
\hline LNJZ & 121.740 & 39.092 & $0.013 \pm 0.0019$ & $0.000 \pm 0.0018$ & -0.055 \\
\hline LNSY & 123.579 & 41.827 & $0.017 \pm 0.0024$ & $-0.003 \pm 0.0024$ & -0.070 \\
\hline LNYK & 122.603 & 40.684 & $0.015 \pm 0.0019$ & $-0.003 \pm 0.0019$ & -0.055 \\
\hline LUZH & 105.414 & 28.872 & $0.001 \pm 0.0022$ & $0.000 \pm 0.0020$ & -0.008 \\
\hline NMAG & 122.627 & 43.303 & $0.014 \pm 0.0017$ & $-0.003 \pm 0.0017$ & -0.053 \\
\hline NMAL & 120.113 & 43.863 & $0.011 \pm 0.0020$ & $-0.002 \pm 0.0020$ & -0.056 \\
\hline NMDW & 116.963 & 45.513 & $0.008 \pm 0.0019$ & $-0.001 \pm 0.0019$ & -0.057 \\
\hline NMER & 123.727 & 50.576 & $0.006 \pm 0.0021$ & $-0.003 \pm 0.0022$ & -0.037 \\
\hline NMTK & 111.252 & 40.261 & $0.005 \pm 0.0018$ & $0.001 \pm 0.0017$ & -0.037 \\
\hline NMWL & 122.027 & 46.041 & $0.011 \pm 0.0027$ & $-0.001 \pm 0.0027$ & -0.060 \\
\hline NMZL & 115.980 & 42.233 & $0.008 \pm 0.0020$ & $-0.001 \pm 0.0020$ & -0.051 \\
\hline SDCY & 119.460 & 36.754 & $0.010 \pm 0.0019$ & $0.001 \pm 0.0018$ & -0.055 \\
\hline SDJX & 116.351 & 35.427 & $0.007 \pm 0.0018$ & $0.001 \pm 0.0017$ & -0.044 \\
\hline SDLY & 118.288 & 35.000 & $0.008 \pm 0.0022$ & $0.001 \pm 0.0021$ & -0.051 \\
\hline SDQD & 120.304 & 36.077 & $0.011 \pm 0.0018$ & $0.000 \pm 0.0017$ & -0.056 \\
\hline
\end{tabular}


(Continued)

\begin{tabular}{|c|c|c|c|c|c|}
\hline \multirow{2}{*}{ Station } & \multicolumn{2}{|c|}{ Station location } & \multicolumn{3}{|c|}{ Coseismic displacement } \\
\hline & Longitude $\left({ }^{\circ}\right)$ & Latitude $\left(^{\circ}\right)$ & East (m) & North (m) & Correlation \\
\hline SDRC & 122.421 & 37.170 & $0.014 \pm 0.0020$ & $0.001 \pm 0.0019$ & -0.062 \\
\hline SDYT & 121.436 & 37.483 & $0.013 \pm 0.0019$ & $0.001 \pm 0.0018$ & -0.056 \\
\hline SDZB & 117.992 & 36.806 & $0.009 \pm 0.0020$ & $0.001 \pm 0.0019$ & -0.050 \\
\hline SHAO & 121.200 & 31.100 & $0.006 \pm 0.0017$ & $0.001 \pm 0.0015$ & -0.066 \\
\hline SUIY & 130.908 & 44.433 & $0.028 \pm 0.0020$ & $-0.015 \pm 0.0021$ & -0.062 \\
\hline SXCZ & 113.180 & 36.225 & $0.005 \pm 0.0021$ & $0.001 \pm 0.0020$ & -0.060 \\
\hline SXDT & 113.392 & 40.122 & $0.006 \pm 0.0019$ & $0.000 \pm 0.0018$ & -0.044 \\
\hline SXGX & 111.900 & 36.252 & $0.004 \pm 0.0023$ & $0.001 \pm 0.0022$ & -0.037 \\
\hline SXLF & 111.371 & 36.084 & $0.004 \pm 0.0020$ & $0.001 \pm 0.0019$ & -0.041 \\
\hline SXLQ & 114.021 & 39.382 & $0.006 \pm 0.0020$ & $0.001 \pm 0.0019$ & -0.055 \\
\hline SXTY & 112.433 & 37.712 & $0.005 \pm 0.0020$ & $0.001 \pm 0.0019$ & -0.041 \\
\hline TAIN & 117.123 & 36.214 & $0.009 \pm 0.0020$ & $0.001 \pm 0.0019$ & -0.049 \\
\hline TJBD & 117.399 & 39.697 & $0.009 \pm 0.0019$ & $0.000 \pm 0.0019$ & -0.050 \\
\hline TJBH & 117.689 & 39.084 & $0.009 \pm 0.0021$ & $0.000 \pm 0.0020$ & -0.051 \\
\hline WUHN & 114.357 & 30.532 & $0.003 \pm 0.0023$ & $0.001 \pm 0.0020$ & -0.043 \\
\hline XIAA & 108.986 & 34.178 & $0.003 \pm 0.0016$ & $0.000 \pm 0.0015$ & -0.017 \\
\hline XIAM & 118.083 & 24.450 & $0.001 \pm 0.0023$ & $-0.001 \pm 0.0019$ & -0.058 \\
\hline XNIN & 101.774 & 36.601 & $0.001 \pm 0.0017$ & $0.000 \pm 0.0016$ & 0.002 \\
\hline YANC & 107.437 & 37.779 & $0.003 \pm 0.0020$ & $0.000 \pm 0.0019$ & -0.018 \\
\hline ZHNZ & 113.105 & 34.521 & $0.004 \pm 0.0018$ & $0.001 \pm 0.0017$ & -0.035 \\
\hline ZJJD & 119.274 & 29.475 & $0.004 \pm 0.0020$ & $0.000 \pm 0.0018$ & -0.056 \\
\hline ZJWZ & 120.763 & 27.934 & $0.004 \pm 0.0019$ & $0.000 \pm 0.0017$ & -0.065 \\
\hline ZJZS & 121.989 & 30.071 & $0.005 \pm 0.0019$ & $0.001 \pm 0.0018$ & -0.068 \\
\hline AIRA & 130.600 & 31.824 & $0.013 \pm 0.0024$ & $0.002 \pm 0.0022$ & -0.068 \\
\hline $\mathrm{CCJ} 2$ & 142.195 & 27.068 & $0.001 \pm 0.0022$ & $-0.002 \pm 0.0021$ & -0.079 \\
\hline CNMR & 145.743 & 15.230 & $0.001 \pm 0.0029$ & $0.000 \pm 0.0027$ & -0.015 \\
\hline DAEJ & 127.374 & 36.399 & $0.023 \pm 0.0019$ & $0.002 \pm 0.0018$ & -0.064 \\
\hline GUAM & 144.868 & 13.589 & $0.001 \pm 0.0030$ & $0.001 \pm 0.0029$ & -0.175 \\
\hline IRKT & 104.316 & 52.219 & $0.001 \pm 0.0015$ & $0.000 \pm 0.0015$ & 0.012 \\
\hline $\mathrm{KGNI}^{*}$ & 139.488 & 35.710 & $0.239 \pm 0.0030$ & $0.058 \pm 0.0035$ & -0.163 \\
\hline KHAJ & 135.046 & 48.521 & $0.011 \pm 0.0020$ & $-0.011 \pm 0.0021$ & -0.034 \\
\hline KSMV $^{*}$ & 140.658 & 35.955 & $0.716 \pm 0.0028$ & $-0.035 \pm 0.0032$ & -0.186 \\
\hline MCIL & 153.979 & 24.290 & $-0.006 \pm 0.0023$ & $0.006 \pm 0.0021$ & -0.055 \\
\hline MTKA $^{*}$ & 139.561 & 35.680 & $0.236 \pm 0.0025$ & $0.057 \pm 0.0025$ & -0.099 \\
\hline PETS & 158.650 & 53.023 & $0.001 \pm 0.0020$ & $0.001 \pm 0.0025$ & 0.013 \\
\hline STK2 & 141.845 & 43.529 & $0.017 \pm 0.0023$ & $-0.025 \pm 0.0024$ & -0.041 \\
\hline SUWN & 127.054 & 37.276 & $0.024 \pm 0.0020$ & $0.001 \pm 0.0019$ & -0.099 \\
\hline TSKB $^{*}$ & 140.087 & 36.106 & $0.547 \pm 0.0020$ & $0.051 \pm 0.0020$ & -0.103 \\
\hline TWTF & 121.165 & 24.954 & $0.003 \pm 0.0021$ & $-0.002 \pm 0.0017$ & -0.064 \\
\hline ULAB & 107.052 & 47.865 & $0.003 \pm 0.0015$ & $0.000 \pm 0.0015$ & 0.004 \\
\hline USUD* & 138.362 & 36.133 & $0.219 \pm 0.0024$ & $0.048 \pm 0.0024$ & -0.102 \\
\hline YSSK & 142.717 & 47.030 & $0.002 \pm 0.0019$ & $-0.001 \pm 0.0023$ & -0.053 \\
\hline
\end{tabular}

* represents the IGS station in Japan, whose coseismic displacements were derived from 18-h data after the main shock.

is different from increased seismic activities we observed in the Sichuan-Yunnan region after the 2004 Sumatra earthquake [11]. This also suggests that the effects of the Tohoku-oki earthquake on faults in Northeast and North China are limited.
It is worth mentioning that large earthquakes affect regional stress-strain field. This effect can last for years, decades, or even centuries as the results of afterslip on the fault plane and viscoelastic relaxation in the lower crust and upper mantle. Previous studies have shown that in some 


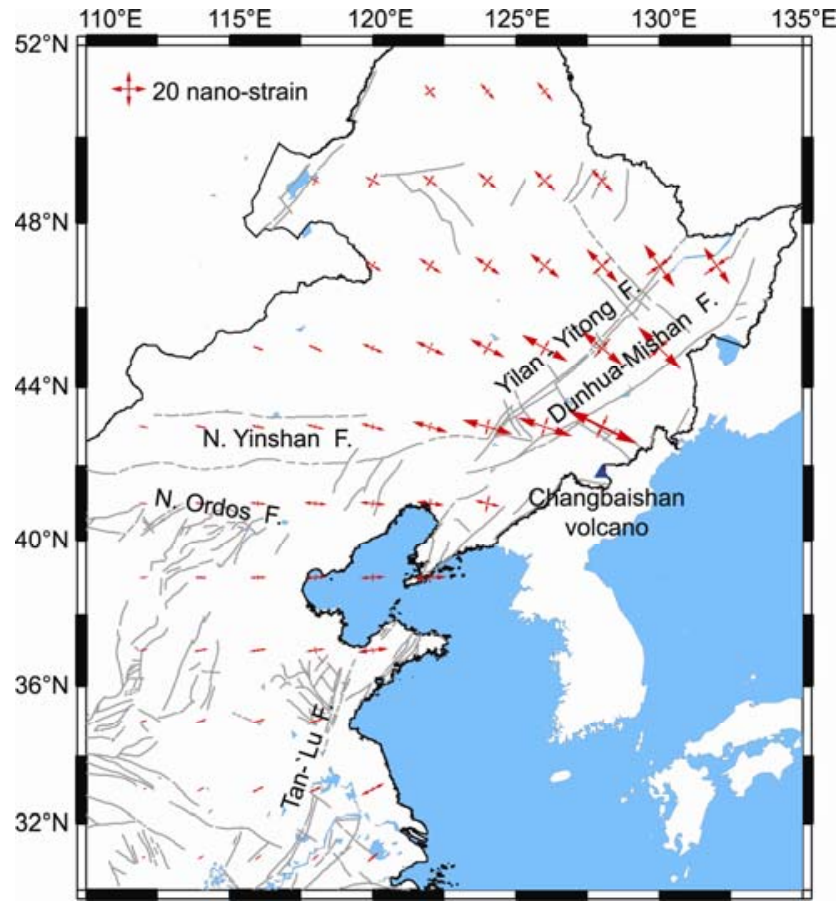

Figure 2 Horizontal principal strain components caused by the Tohoku-oki earthquake.
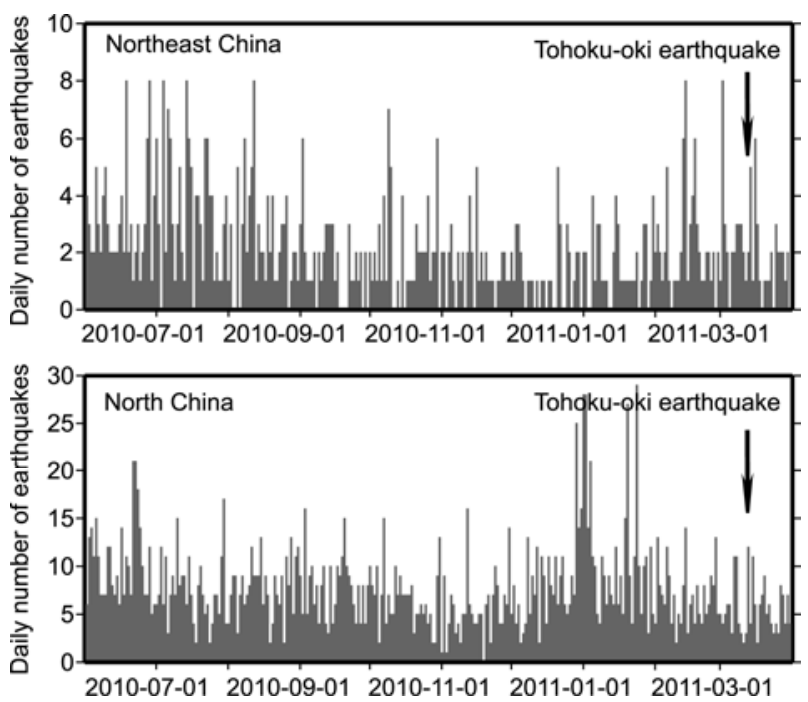

Figure 3 Frequencies of earthquakes in Northeast and North China before and after the Tohoku-oki earthquake.

cases the seismic moment released by afterslip following large interplate earthquakes could even be comparable to that released by the coseismic rupture [12-14]. Thus viscoelastic relaxation in the lower crust and upper mantle could affect much wider regions. Therefore, to further understand tectonic loading processes and associated changes of earthquake potentials, in the next few years we need to monitor the temporal evolution of the stress-strain field caused by the Tohoku-oki earthquake by analyzing GPS data from TEONET. At the same time, it will be necessary to continue studying the triggering effect of the Tohoku-oki earthquake on the Changbaishan volcano, and closely monitor volcanic activity in the region to provide a basis for earthquake disaster mitigation in Northeast and North China.

After the Tohoku-oki earthquake, GPS observations from TEONET allowed us to immediately assess the change in crustal movement caused by the earthquake. Also, the observations make up an important and fundamental dataset for understanding earthquake rupture processes. Compared with GPS observations from episodic campaign surveys, continuous GPS observations are more efficient and more accurate for capturing coseismic and postseismic deformation fields and their temporal evolution. The completion and operation of TEONET enhances abilities to monitor crustal deformation, capture earthquake precursors, and gain insights into the entire spatiotemporal deformation field associated with tectonic and seismogenic processes.

The authors gratefully acknowledge the suggestions of anonymous reviewers that helped in improving the quality of the paper. This work was supported by the State Key Laboratory of Earthquake Dynamics (LED2009A02) and the National Key Infrastructure Project "Tectonic and Environmental Observation Network in China".

1 DeMets C, Gordon R G, Argus D F, et al. Geophys Res Lett, 1994, 21: 2191-2194

2 Herring T A, King R W, McClusky S C. GAMIT reference manual: GPS Analysis at MIT. Release 10.4. Department of Earth, Atmospheric, and Planetary Sciences, Massachusset Institute of Technology, Cambridge MA, 2010

3 Okada Y. Bull Seism Soc Am, 1985, 75: 1135-1154

4 Sun W B, He Y S, Li Y B. Acta Seismol Sin, 1985, 7: 33-44

5 Meng X S, Zheng H, Jiang J H. Seismol Res Northeast Chin, 2003, 19: 13-18

6 Li W Y, Wang X Y. Earthquake, 1996, 16: 219-224

7 Shen Z-K, Jackson D D, Ge B X. J Geophys Res, 1996, 101: 27957-27980

8 Min W, Jiao D C, Zhou B G, et al. Seismol Geol, 2011, 33: 141-150

9 Walter T R, Amelung F. Geology, 2007, 35: 539-542

10 Wang F, Shen Z K, Wang Y Z, et al. Chinese Sci Bull, 2011, 56: 2077-2081

11 Wang M, Zhang P Z, Shen Z K, et al. Chinese Sci Bull, 2006, 51: 1771-1775

12 Heki K, Miyazaki S, Tsuji H. Nature, 1997, 386: 595-598

13 Nishimura T, Miura S, Tachibana K, et a1. Tectonophysics, 2000, 323: 217-238

14 Ozawa S, Kaidzu M, Murakami M, et a1. Earth Planets Space, 2004, 56: $675-680$

Open Access This article is distributed under the terms of the Creative Commons Attribution License which permits any use, distribution, and reproduction in any medium, provided the original author(s) and source are credited. 